\title{
OS DESAFIOS DA EDUCAÇÃO BRASILEIRA
}

BASTOS, Manoel de Jesus ${ }^{1}$

BASTOS, Manoel de Jesus. Os Desafios da Educação Brasileira. Revista Científica Multidisciplinar Núcleo do Conhecimento. Ano 02, Ed. 01, Vol. 14, pp. 39-46 Janeiro de 2017 ISSN:2448-0959

\section{RESUMO}

A educação brasileira vivencia grandes desafios na atualidade. De um lado a fomentação pela ampliação estatística de uma "Pátria Educadora" e de um país sem analfabetos, do outro a necessidade, gritante, por maiores investimentos, na formação inicial e continuada dos professores, reparação e adequação das estruturas físicas das escolas e, é claro, maior preocupação e comprometimento com a sua qualidade. Apresenta-se, como embasamento norteador do processo educacional, as metas do Plano Nacional de Educação e os artigos da Lei de Diretrizes e Bases da Educação Nacional mas não são cumpridos. Enquanto não houver a valorização devida, o respeito com os seus profissionais e uma política exclusiva na área, com fiscalização permanente dos recursos destinados, vai haver sempre essa dicotomia entre teoria e prática, pois os cidadãos conscientes e preparados para os exercícios de suas cidadanias e qualificação para o trabalho, conforme prevê as leis da educação, ainda são aguardados pela sociedade.

Palavras-Chave: Educação, Qualidade, Cidadão, Sociedade, Formação.

\footnotetext{
${ }^{1}$ Formado em Normal Superior pela UESPI (Universidade Estadual do Piauí), Pósgraduado em Supervisão Escolar pela Faculdade de Teologia Hokemãh - Fateh e Mestrando em Educação pela Anne Sullivan University.
} 


\section{INTRODUÇÃO}

A Lei de Diretrizes e Bases da Educação Nacional - LDBEN, garante em seu artigo $2^{\circ}$, que a educação é um direito de todos, dever do estado e da família e que visa o pleno desenvolvimento do indivíduo, seu preparo para o exercício da cidadania e a qualificação para o trabalho. Um país ou uma nação dificilmente avançará, positivamente, se não investir, seriamente, no setor educacional. Para tanto, é necessário que o estado ofereça uma educação básica de qualidade, preenchendo todos os requisitos previstos nas leis do sistema. A redução das desigualdades sociais sinalizam o desmoronamento a partir de tais princípios. Garantir o direito à entrada e à permanência do aluno na escola, não seria suficiente, as necessidades de uma educação qualitativa vão muito além que isso. São vários fatores que contribuem, negativamente, na qualidade da educação básica: a falta da formação inicial e continuada do professor, inadequação do ambiente, carência de materiais de suporte pedagógico, número excessivo de alunos por sala, baixa remuneração dos professores, carga horária excessiva, curta jornada escolar das crianças e dos jovens recomendadas nos estudos educacionais.

É impossível, portanto, analisar qualquer conjuntura ou sugerir soluções, sem mensurar a complexidade das inter-relações entre a educação e a sociedade. Para a efetivação de uma política educacional, faz-se necessário o ombreamento com outras políticas sociais que sinalizem o combate à pobreza, maior distribuição de renda e melhores condições de vida das famílias que mantêm os filhos na escola pública.

Grosso modo, falta uma política educacional rigorosa no enfrentamento dos problemas, na busca das soluções e no cumprimento das leis educacionais. É impossível oferecer uma escolarização de qualidade em um ambiente com estrutura precária e sem contar que muitas instituições não dispõem do seu Projeto PolíticoPedagógico - PPP, exigido pela Lei de Diretrizes e Bases da Educação Nacional LDBEN.

De modo que o quadro representativo das precariedades educacionais, exige um esforço coletivo, com o compartilhamento de todos os segmentos da sociedade e, 
como já foi mencionado, políticas que elevem o investimento da educação no Brasil, com planejamento eficaz e fiscalização rígida, procurando valorizar a profissão docente, elevar a qualidade do ensino e superar o déficit quantitativo dos profissionais em educação em numerosas escolas do país.

\section{OS DESAFIOS DA EDUCAÇÃO BRASILEIRA NA ATUALIDADE}

É admissível, que há um grande consenso no que diz respeito a baixa qualidade do ensino nas escolas públicas do nosso país. Infelizmente, a qualidade da escola pública no Brasil tem sido motivo de preocupação, tanto do governo quanto da sociedade, pois as várias tentativas de melhorá-la ainda não surtiram efeito.

Há alguns anos a escola pública preocupava-se mais com a qualidade do ensino e dispensava a estatística numerológica quantitativa. Passavam de ano aqueles que conseguiam acompanhar o processo do ensino-aprendizagem, sem receber tantas chances flexíveis. Entre $50 \%$ à $60 \%$, deste, estavam realmente preparados para a série subsequente, no ano seguinte. Não existia degraus fracos que sinalizassem problemas no futuro e a sequência oferecia a garantia de uma formação segura para o indivíduo.

A democratização acelerada das escolas públicas brasileiras, em finais do século $X X$, flexibilizou, demasiadamente, o sistema educacional, comprometendo a sua qualidade. $O$ estado brasileiro não tem demonstrado nenhum interesse de investir repetidamente no aluno, que por algum motivo tenha ficado retido, mas propicia a sua passagem, mesmo aleatoriamente, para 0 ano seguinte. A evidência da baixa participação da família, no processo do ensino-aprendizagem, também é fato e que, de certo modo, contribui, negativamente, com a desaceleração no processo escolarização, o que leva a crer que, como a maioria dos pais de alunos não passaram pela escola, faltam-Ihes conhecimentos sobre as características de uma escola de qualidade, deixando de dar ênfase uma das ações mais importantes da vida: a valorização da escolarização para os seus filhos. 
Acredita-se que um, dentre os tantos problemas que afetam a qualidade da educação no Brasil, é o fato de a classe média deixar a escola pública, tendo em vista que essa classe dispõe de maior propriedade para discutir e exigir as características de uma educação que deixe de fazer de conta e prepare melhor os seus educandos para os futuros desafios da vida. Está faltando engajamento na defesa de uma escola que atenda às necessidades básicas do educando, previstas na LDB, e um esforço cultural para a construção consolidada da verdadeira cidadania.

\section{RECURSOS QUE FINANCIAM A EDUCAÇÃO PÚBLICA NO BRASIL}

Segundo dados do Instituto Nacional de Estudos e Pesquisas Educacionais Anísio Teixeira - INEP, um dos desafios essenciais para a efetivação de uma educação de qualidade, em nosso país, estaria relacionado no Produto Interno Bruto - PIB, que hoje investe, aproximadamente $5 \%$ com educação, um percentual considerado baixo por não atender a demanda, tendo em vista que o número de alunos é muito alto e quando o investimento é dividido fica diluído. A exemplo disso é que a educação de um brasileiro é feita com apenas um terço do valor gasto com um estudante dos países ricos, em média. Porém na previsão da Meta 20 do novo PNE (Plano Nacional de Educação) o gasto do PIB com a educação deverá ser de $7 \%$ até o quinto ano vigente e $10 \%$ até o final do decênio. Uma outra garantia de recursos para o setor educacional é a da receita, resultante de impostos recolhidos e transferências, onde a união deve aplicar até $18 \%$ e estados e municípios no mínimo de $25 \%$.

Todavia, a implementação de Leis no setor educacional como a LDB (9394/96), o Piso Salarial Nacional do Magistério, Lei ํo 11.378/2008, o Fundo de Manutenção e Desenvolvimento da Educação Básica e Valorização dos Profissionais do Magistério - FUNDEB, os Planos de Carreira Cargos e Salários do Magistério, além de outras, tem proporcionado um crescimento valorativo nos últimos anos.

A defesa de aumento de verbas públicas para a educação deve ser contínua, porém não se deve ofuscar de que é preciso gastar adequadamente, tendo em vista que um dos mais acentuados problemas são os aviltantes desvios. Fazer uma boa gestão dos recursos financeiros, significa sinalizar um amplo desenvolvimento educacional no 
que diz respeito a sua qualidade, necessária aos que apostam na educação como acesso ao melhor caminho para a ascensão social.

\section{A DESVALORIZAÇÃO DA PROFISSÃO DOCENTE}

Desde alguns anos, a imprensa vem apresentando dados negativos à respeito da área pedagógica, onde a maioria dos jovens já não se incluem em suas perspectivas, a profissão docente, o que leva a crer que em pouco tempo, talvez, cheque-se a uma crise deficitária desses profissionais, haja vista, a falta de valorização no setor. A profissão está, cada dia que passa, perdendo o poder de atração e sedução dos jovens talentos. Os jovens não querem gastar suas energias psicológicas nessa área, por saber que não oferece uma remuneração e reconhecimento merecidos, apesar de conhecer a sua relevância.

Resultados de pesquisas no Brasil e no mundo, apontam que as sociedades consideram a profissão pedagógica como uma das mais importantes socialmente, por ser a que proporciona a formação de todos os profissionais das mais distintas áreas no planeta. E então, por que não é valorizada e reconhecida pela sociedade?

No entanto, alguns estudos tem demonstrado que, um dentre tantos problemas, que sinalizam a falta de interesse à profissão docente, é a questão salarial, desmotivando, assim, os jovens que dispensam interesse por uma área que retribui tão mal economicamente, pois grande parte dos professores, vivem abarrotados de atividades, inclusive complementares, buscando outras fontes de renda para poder atender as suas necessidades e de suas famílias.

Acredita-se, ainda, que outro aspecto negativo em relação ao desenvolvimento educacional, seja a falta de políticas públicas que atendam às necessidades das novas gerações, oferecendo novos saberes e competências que motivem a aceleração e a fomentação pelo processo educativo, pois as precárias condições de formação, trabalho e a baixa oferta remunerativa, empecilham que os professores tenham acessibilidade aos saberes e competências qualitativas. O estado tem 
adotado sempre as mesmas medidas sem, no entanto, mensurar a evolução tecnológica e as necessidades do seu acompanhamento.

É sabido que as experiências dos professores refletem, nitidamente, nos alunos positiva ou negativamente. Como poderiam escolher uma profissão na qual tem observado, durante toda a sua juventude, os choramingas dos professores desmotivados pela remuneração que não Ihes proporciona comodidade e satisfação? Contudo, no exercício do magistério, sempre haverá problemas, no processo educacional, uma vez que o professor, por mais bem preparado que esteja, Ihes faltarão condições que possibilitariam melhor desempenho.

\section{A EXPANSÃO DA EDUCAÇÃO INFANTIL E O AUMENTO DE PERMANÊNCIA NA ESCOLA}

O novo Plano Nacional de Educação - PNE, prevê em sua primeira meta, a universalização da educação infantil, até 2016, na pré-escola, para as crianças entre 4 e 5 anos e ampliar a oferta de educação infantil em creches, chegando a $50 \%$, no mínimo, às crianças de 0 a 3 anos até 2014. A pontaria teórica da Lei engrandece a todos o que tem fomentação imensurável pela melhoria da qualidade da educação e aposta na construção de pilares sólidos para a consolidação de uma formação cidadã. A base educacional carece dessa atenção para evidenciar sucesso no seu trajeto educacional. Isso é mais do que a antecipação da educação obrigatória e a oferta de possibilidades das crianças passarem a maior parte do tempo na escola, que além de obterem uma melhor formação, dão oportunidade para suas mães trabalharem fora de casa.

A ampliação de permanência na escola, abre leques de oportunidades tanto para crianças quanto para jovens, atribuindo, de certa forma, uma escolarização mais efetiva e mais completa. A oferta de maior tempo diário na escola é, portanto, um grande desafio para as escolas públicas no Brasil, tendo em vista, a obrigatoriedade de ampliação e adequação dos espaços físicos das instituições educacionais, aquisição de equipamentos, qualificação do quadro de pessoal, melhoria nas condições de gestão e de acessibilidade, estimulação de formação inicial e continuada 
dos profissionais da educação infantil, além de outros suportes imprescindíveis ao seu funcionamento integral.

A construção de um consenso à respeito da importância da expansão e valorização da educação infantil, sinaliza mudanças positivas às futuras gerações, levando em consideração que o investimento no alicerce de uma construção oferece uma garantia em todo o percurso formativo, sem riscos de desmoronamento. Esse aumento do tempo é considerado como "necessário" para que o cidadão possa cumprir e efetivar com o que reza o $2^{\circ}$ artigo da LDB: " A educação ... tem por finalidade o pleno desenvolvimento do educando, seu preparo para o exercício da cidadania e sua qualificação para o trabalho".

\section{A EXPANSÃO DO ENSINO SUPERIOR PÚBLICO}

É observável que o ensino superior no Brasil, vem se expandindo bastante nos últimos anos, tanto no setor público quanto no privado. Aliás, o Brasil é um dos países com uma das maiores taxas em matrículas no ensino superior. O que falta é a garantia da qualidade da formação oferecida, pois muitas são as instituições privadas itinerantes que aparecem atraindo jovens, que não tiveram oportunidade de cursar uma universidade pública e terminam enveredando-se por essas que aparecem por acaso.

Todavia, é admissível que existe um crescimento muito grande no que diz respeito as matrículas no ensino superior no Brasil, atualmente, porém a preocupação não deixa de ser proporcional a esse crescimento, uma vez que o que faria a diferença seria a qualidade e não obstante, a quantidade mencionada nas estatísticas brasileiras. Esse crescimento tem se intensificado também, na formação de mestres e doutores em áreas distintas do conhecimento. De modo que o avanço científico e tecnológico, sinaliza o alcance dos patamares de formação de mestres e doutores de outros países.

Entende-se como um grande desafio, as necessidades de formação impostas para o prosseguimento do ensino superior, por saber que grande parte dos professores que trabalham nas instituições de ensino superior, não possuem curso de mestrado ou 
doutorado. Se existe, por um lado, possibilidades de inserção nos cursos superiores, mais precisamente, em mestrados e doutorados, por outro existe os empecilhos burocráticos que dificultam a sua consolidação.

No entanto, se descarta as possibilidades de superação dos desafios propostos, no âmbito das políticas de ciências tecnológicas, a partir do momento em que priorizarse a produção de conhecimentos e a preocupação com a formação real de recursos humanos na área educacional. É imprescindível que haja uma política mais responsável que possa oferecer a fomentação pela formação inicial e continuada de professores.

\section{CONSIDERAÇÕES FINAIS}

Apesar da intensidade dos desafios da educação em nosso país, acredita-se numa mudança positiva a partir do momento em que a própria sociedade reconhecer a importância e necessidade de uma educação de qualidade, fazendo parte dela e exigindo os cumprimentos legais previstos nas leis. As previsões teóricas a respeito da educação brasileira são lineares, contudo, há uma dicotomia muito acentuada em relação a prática.

As possibilidades de melhoria no sistema educacional brasileiro existe, desde que haja um investimento planejado na formação dos professores e um olhar de valorização na área e que os recursos previstos e destinados à educação sejam radicalmente fiscalizados, para que deixem de entrar pelos ralos desnorteadores de políticos descompromissados e desinteressados com o desenvolvimento da sociedade.

É admissível afirmar que investir bem na educação é, ao mesmo tempo, apostar em um futuro próspero, de pessoas bem sucedidas e de cidadãos conscientes, capazes de cumprir com as obrigações que lhes são exigidas e com os direitos que the são devidos. 
Os desafios da educação brasileira não são, simplesmente, exclusivos dos seus profissionais, mas de toda a sociedade que almeja uma nação desmascarada e consciente, pois uma pátria que não reconhece a educação como pilar do equilíbrio social, jamais se estabilizará.

\section{REFERÊNCIAS}

CARVALHO, Antônio Luiz Afonso - Presidente da Província de Minas Gerais, 1871. Constituição da República Federativa do Brasil, 1988.

FILHO, Luciano Mendes de Farias - Faculdade de Educação da Universidade Federal de Minas Gerais (UFMG), Coordenador do Projeto Pensar a Educação, Pensar o Brasil. Instituto Nacional de Estudos e Pesquisas Educacionais Anísio Teixeira (INEP).

LDB - Lei no 9.394, de 20 de dezembro de 1996, 11ª ed. Ministério da Educação, 1996. Plano Nacional de Educação, Lei no 13.005 de 25 de junho de 2014. 